\title{
Statistical Methods for Planning Diesel Engine Overhauls in the U. S. Coast Guard
}

\author{
C. M. Milkie and Dr. A. N. Perakis
}

\begin{abstract}
The United States Coast Guard has recently investigated new strategies to maintain cutter propulsion diesel engines. Reliability centered maintenance with statistical methods may allow the time between costly scheduled overhauls to be increased. One indicator of engine aging is the number of failures experienced with increasing operating hours. The purpose of this paper is to investigate the failure-time relationship of the ALCO 251 marine diesel propulsion engine operated on Reliance class cutters. This analysis used exponential, Weibull, and three-part composite Weibull failure density functions to model engine casualty data dating back to 1978. The data does not indicate the source of the engine failure, but
\end{abstract}

every failure had a significant operational impact. Results indicate an increasing failure rate as the engine ages to the 24,000 hour overhaul time. The evidence indicates a constant failure useful life region, but the increasing failure rate from the Weibull models suggests that the periodic overhauls do not prevent wearout failures. As a result, the Coast Guard should consider refining diesel engine overhaul policy in order to prevent increasing age-related failures.

\section{Introduction}

Increasing pressure on organizational maintenance functions has spurred various maintenance management initiatives in the past thirty years. Faced with an aging cutter fleet, challenging operations tempo, and a multitude of missions, the United States Coast Guard (USCG) is currently investigating new Fleet maintenance policies. Reliability centered maintenance (RCM) strategies help determine what maintenance tasks to perform and when. RCM decision algorithms attempt to maximize system contribution to organizational goals by reducing downtime, expense, environmental, and safety hazards while providing insight into the true capabilities of a given asset.

One work-intensive maintenance action is the routine overhaul of main propulsion diesel engines (MDEs). Under the traditional guidelines, for the three white-hull (Reliance, Secretary, and Famous) classes, the Coast Guard will overhaul a main diesel engine six times a year at an approximate cost of $\$ 250,000$ in parts and 3000 labor hours per overhaul. This overhaul typically consists of removing and inspecting all pistons and liners and major ancillaries and making selected component replacements. Incorporating RCM to defer or eliminate these costly overhauls would bring substantial savings.

The intention of the engine overhaul is to restore the life and reliability of the propulsion diesel engine. Figure 1 shows the classic view of the relationship between failure rate and operating time. A new system may experience more than normal failures during the "burn-in" phase, followed by a period of 


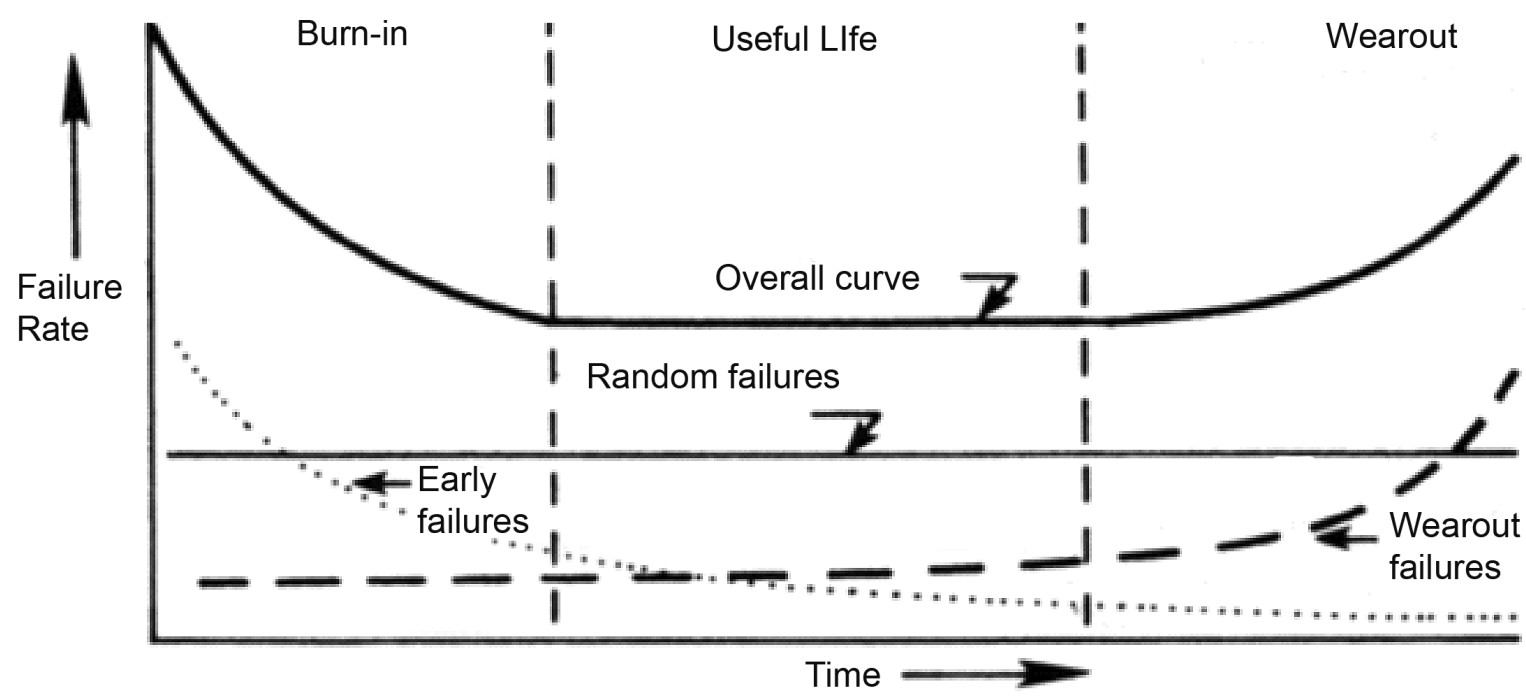

FIGURE 1:

Bathtub Curve (Smith, D. 1997) steady or normal amount of failures, and lastly, again more than normal failures as components wearout. These relationships and the corresponding Weibull shape parameter $\beta$ (which will be explored later in this report) are listed in Table $\mathbf{1}$. Ideally, a scheduled overhaul is performed at a time near the end of what is called the "useful life" in Figure 1 and restores the reliability to a point near the beginning of this useful life region. Under the RCM philosophy, a timebased overhaul will have little effect on engine failure modes which are not related to operating time, or related the time selected for the overhaul interval.

Yet time-based overhauls have many advantages. First, consistent budget planning for support functions can ease financing variability. Second, performing all major engine maintenance at the same time may have the

\section{Table 1}

Bathtub Curve Aging Regions

\begin{tabular}{|c|c|c|c|}
\hline Interval & Failure Rate & $\beta$ & Typical Failure Modes \\
\hline Infant Mortality & Decreasing & $<1$ & $\begin{array}{l}\text { manufacture, QA, impurities, } \\
\text { incorrect adjustment, alignment, } \\
\text { installation }\end{array}$ \\
\hline Random Failures & Constant & $=1$ & stress-related, environmental \\
\hline Wearout Failures & Increasing & $>1$ & $\begin{array}{l}\text { corrosion, oxidation, } \\
\text { friction wear, fatigue }\end{array}$ \\
\hline
\end{tabular}

lowest average impact on asset availability. Third, institutional structure and knowledge support scheduled overhauls (and viceversa). Finally, correctly timed overhauls prevent the increase in engine failure rate for those wearout failures which would otherwise occur for an engine operating in the "wearout" region.

Executing scheduled overhauls risks several operational impacts. First, very often the overhaul poses the hazard of misalignment or improper installation of new components. Likewise, many operators will attest to an increase in engine casualties during a period after an overhaul. Lastly, the scheduled diesel engine overhauls disrupt a cutter's inport routine with an immense resource drain.

Time-based overhauls to refurbish or replace major engine components may not be appropriate if engine failures are not time related. Usually, the engine manufacturer recommends an overhaul interval. The suggested interval may be too short because either the manufacturer has a vested interest to sell replacement parts, considers life-cycle maintenance secondary to other design goals, does not know what environment the engine will be operated in, or needs to reduce potential liability. Another reason to reject the idea of time-based scheduled restoration 
is that under RCM methodologies, equipment fails from a variety of failure modes. Preventive maintenance can manage most failure modes, with properly timed scheduled restoration only appropriate for failure modes of gradual deterioration.

Casualty rate as an engine ages provides one measure of the degree of degradation.

Casualty rate information can be determined from failure data aggregated for an entire cutter class. The Weibull shape parameter $\beta$ can be thought of to be an indicator of rate of change of the failure or casualty rate as shown in Table 1. Ideally, engine failure data identifies the culprit component and failure mode. The data in this analysis is only identified as an operationally significant propulsion diesel engine casualty. This limitation is acceptable because the analysis determines the overall failure rate correlation to engine aging. In the context of RCM, this aging relationship helps judge the appropriateness of a scheduled engine restoration.

\section{Current Coast Guard Diesel Engine Overhaul Planning}

Moore and Perakis (1999) detail several trend monitoring techniques used to predict the need for diesel engine restoration (overhaul). The Navy Oil Analysis Program (NOAP), Full Power Trial (FPT), and Diesel Engine Maintenance Program (DEMP) are supposed to be used in conjunction with engine operating hours to schedule overhaul. Early in this project, the authors analyzed Fleet data from FPTs and DEMPs in an attempt to ascertain engine "health" as correlated with age. The analysis showed no mentionable correlation between the several parameters (hourly lube oil consumed, average exhaust temperature, firing pressures) and engine operating hours. As practiced, these measurements are of little value to planning overhaul intervals on a Fleet-wide scale. Until recently, the USCG has relied almost exclusively on time-based, scheduled restoration of the diesel engine.
The Coast Guard Naval Engineering Manual outlines procedures for lube oil spectrographic analysis. Cutters rely on NOAP quarterly analyses to indicate the condition of the engine. Spectrographic analysis detects an increase in wear metals above an established threshold. According to Moubray (1998), AE spectroscopy can detect most wear metals, corrosion, and extraneous contaminants up to several months before an operational failure. Consistent sampling is critical to predicting any incipient failure with the NOAP.

Other condition monitoring techniques aid overhaul planning. One method, engine vibro-acoustic analysis, shows promise for determining overall engine "health." At the time this report was written, Coast Guard policy was to extend the 24,000 hour overhaul upon operator's request up to 28,000 hours. At 28,000 hours the cutter may extend the overhaul to 32,000 hours after an extensive vibro-acoustic analysis. This and other condition-based methods are continually being investigated, improved, and implemented. The new USCGC Healy (WAGB 20) fully incorporates vibration monitoring as part of the regular preventive maintenance (Burt, et al. undated draft). The Atlantic Fleet maintenance command has contracted out condition-monitoring "snapshots" for older engines. An analysis on the USCGC Seneca (WMEC 906) concluded that the scheduled top-end engine overhaul may be deferred (MPR 1998).

\section{Data and Methodology}

Comprehensive failure data should be available for a reliability analysis. Sources of data include cooperative organizations such as the Government-Industry Data Exchange Program (GIDEP), warranty claims for manufacturers, or field data from the operator itself. Data in this report is field data collected at a central location. All Coast Guard units report significant engine casualties (CASREPS) to a central location. The data 
analyzed is an extract from the CASREP

database from 1978-1998. For each reported

CASREP, seven data fields are recorded:

- Hull Number

- Initial Date

- Initial Time

- Completion Data

- Completion Time

- Equipment Indicator Code (EIC)

- Allowance Parts Listing (APL)

The data extract should contain almost all diesel engine corrective maintenance actions. There are several reasons why the data set may underreport the casualties.

To understand reporting inconsistencies, the authors consider how and why a cutter reports casualties. First, the CASREP communicates to operational commands that the cutter's ability is degraded. A casualty may occur and be repaired by an attentive crew before a CASREP needs to be sent. The brief loss in operational ability is without consequence. However, the casualty is important from a systems reliability standpoint because the failure mode may be age related. A second reason for underreporting may be human error by not including the database as an addressee on the CASREP message. The failure would then never be included in any analysis relying on that data. Other drawbacks of the dataset arise from the quality of information contained in each field.

The date and time fields serve as the time reference. Computing mean time between failure (MTBF) and mean time to repair (MTTR) under an exponential assumption may be accomplished by using an average yearly-use multiplier. Maintenance managers schedule MDE overhauls based on the number of operating hours a particular engine has. On average, overhaul planning and determining operating hours at each failure is possible, but ideally the actual engine hours since overhaul would be recorded.

The EIC designates the source of failure. The code may be as specific as "fuel injector" or more general such as propulsion-related. Use of EIC introduces a fundamental question for quantitative reliability analysis: What level of detail is appropriate to collect useful data? Coast Guard CASREPS currently report EIC to identify equipment only, such as "propulsion diesel engine".

Initially, the authors believed the APL would identify the affected component; however, none of the APLs on the data extract could be successfully matched to those from a master list.

\section{The Role of Quantitative Analysis}

Organizations may undertake a RCM program without statistical analysis of their failure histories. However, because many organizations, including the USCG, maintain a database of failure histories, a quantitative analysis of failures can identify a time-dependent failure pattern (Moubray 1997). The age at which an asset demonstrates a significant increase in conditional probability of failure, or hazard rate $(h[t])$, establishes the frequency for scheduled restoration tasks.

A Weibull reliability function (Equation 1) is often used for reliability analysis because of the flexibility to model exponential patterns and non-constant failure rates. Combining different Weibull functions can produce patterns to match any or all regions of the bathtub curve from Figure 1.

$$
\mathrm{R}(\mathrm{t})=\exp \left[-\left(\frac{t-\tau}{\alpha}\right)^{\beta}\right] \alpha
$$

where:

$R(t)=S(t)$ equals the Survivor Function, representing the number of a population remaining in an unfailed state as a function of time $(t)$.

$\alpha$ is the Weibull scale parameter

$\beta$ is the Weibull shape parameter

$\tau$ is the time at which the interval to be modeled begins 


\section{Cumulative Failure Probability}

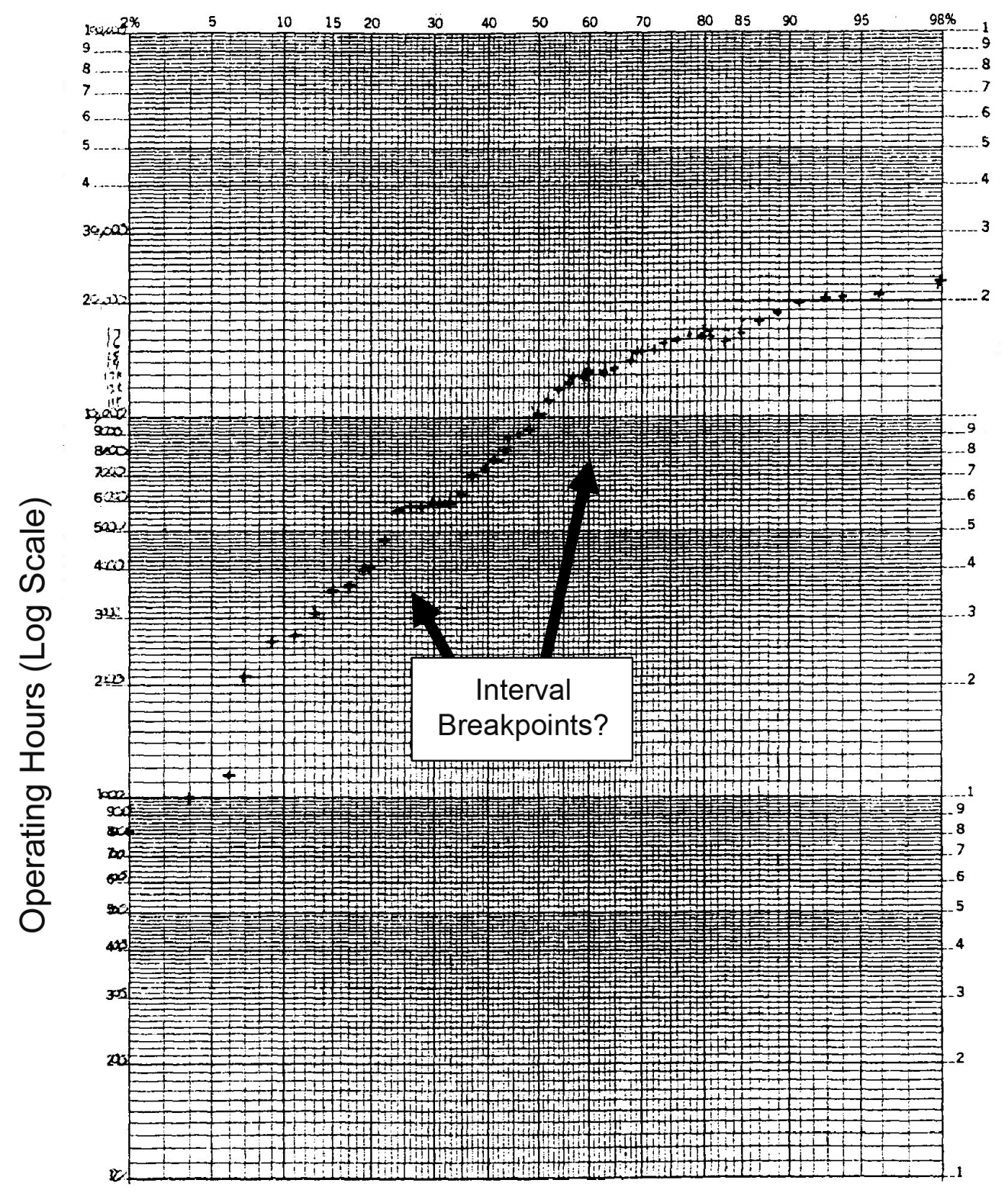

FIGURE 2:

Hand Plot of Casualty

Data on Weibull Paper
A complication arises with the Weibull distribution when modeling a traditional bathtub curve. One or two breakpoints may be selected to compose the curve with Weibull data models. A hand plot (Figure 2) of the failure data gives rough idea of transitions to different failure rate regions by noticing the slope changes on the three line segments roughly fit to the data.
The Weibull plot of the fifty-four diesel engine failures in Figure 2 appears to indicate three regions of differing failure patterns. However, there are several drawbacks to relying solely on interpretation of this graph. Different analysts may select different breakpoints. Depending on the time scale, a slight difference could mean thousands of hours variation for scheduled overhaul interval. 


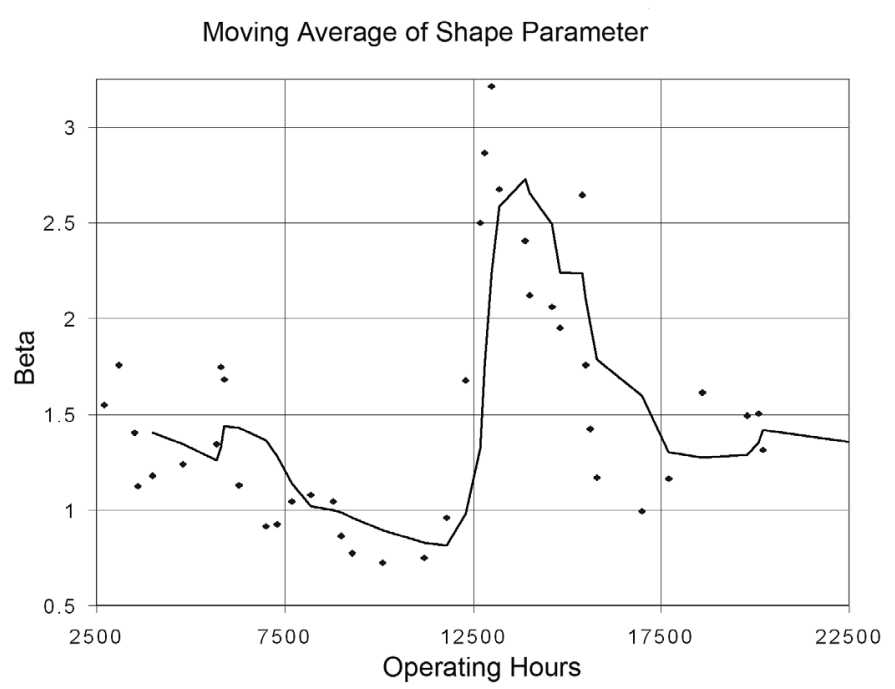

FIGURE 3:

Average Varying Weibull Shape Parameter (Beta - $\beta$ )
Another drawback is inability to plot censored data. A more sophisticated numerical analysis incorporates the fact that some items are replaced before actually failing. Lastly, modern spreadsheet programs provide a convenient avenue to analyze the data rigorously to select breakpoints more consistently. By answering if the failure rate is increasing and to what degree, the analyst can calculate optimal preventive maintenance.

The first step to understanding the aging-failure rate relationship in this analysis is to plot the moving average of the Weibull shape parameter $(\beta)$ on the ordinate with time (operating hours) on the abscissa. It is very easy to see that $\beta$ begins above one, drops to below one (random failures or operating in a "sweet-spot"), followed by a rise to greater than one (wearout). $\beta$ plotted in Figure $\mathbf{3}$ is merely the slope of a seven-point best-fit line on a Weibull plot. Moving a best fit line is more accurate than relying strictly on the analyst to select break points and "fit" a straight line in each region.

\section{Analysis Techniques}

\section{Selecting the Model}

The exponential model was assumed to evaluate Coast Guard casualty performance relative to a 1979 GIDEP summary report on the same model of diesel engine. The CASREP data is easily manipulated to calculate MTBF and MTTR:

$$
\left\{\begin{array}{l}
\text { MTBF }=\frac{1}{\lambda}=\frac{\text { Total Observation Period }}{\text { Total Number of Failures } / \text { Total Systems Exposed }} \\
M T T R=\frac{1}{\mu}=\frac{\text { Total Repair Time }}{\text { Total Number of Failures }}
\end{array}\right\}
$$

The relative performance comparison may only be made in this case with respect to an exponential model due only having summary results in the GIDEP report. An organization may desire failure pattern comparisons instead, which may be accomplished two or more sets of raw failure data.

\section{Weibull Plotting}

The following equation converts data following a Weibull distribution to a linear relationship:

$$
\log \{-\log S(t)\}=\beta \log t-\beta \log \alpha
$$

The slope of the resulting line measures the shape parameter. Once the data is plotted it is easy to distinguish among the three regions. 


\section{Censored Data Techniques}

The data analyzed for this project experience censoring from two sources. First, each engine is overhauled at 24,000 hours. For the purposes of this study, the overhaul resets the clock on each propulsion system. The overhaul is right-censoring, or replacement before failure. If not corrected for, right-censoring skews reliability parameter estimates conservatively. The second censoring occurs because the casualty data extract is only from 1978-1998. All systems under observation are right-censored at the end of the observation period. Six censored events arise from overhauls and five from observation termination for a total of eleven rightcensored events.

Inozu and Perakis (1991) use the Maximum Likelihood Estimate under right censoring. The Maximum Likelihood Estimate was not used for the analysis in this report but is as follows:

$$
\begin{aligned}
& \frac{\sum_{i=1}^{n} t_{i}^{\hat{\beta}} \ln t_{i}}{\sum_{i=1}^{n} t_{i}^{\hat{\beta}}}-\frac{1}{\hat{\beta}}-\frac{1}{r} \sum_{i \in D} \ln t_{i} \\
& \hat{\alpha}=\left[\frac{1}{r} \sum_{i=1}^{n} t_{i}^{\hat{\beta}}\right]^{\frac{1}{\hat{\beta}}}
\end{aligned}
$$

Equations (4) and (5) can be solved simultaneously to find $\alpha$ and $\beta$ from the casualty data.

Another method, which was used for the analysis in this report, is the product-limit (Kaplan-Meier) survivor function $(S(t))$ estimate (Crowder et al. 1991), which is a convenient way to obtain reliability estimates from the data:

$$
\hat{S}(t)=\prod^{(t)}\left(1-\frac{d_{j}}{n_{j}}\right)
$$

Table 2

Results from Exponential Model

\begin{tabular}{lccc} 
& MTBF & MTTR & Availability \\
\hline CASREP & 6350 hours & 257 hours & $91 \%$ \\
\hline GIDEP & 329 hours & 8 hours & $98 \%$ \\
\hline
\end{tabular}

where $d j$ is the number of failures at time $a j$ and $n j$ is the number of items at risk at $a j$ (i.e. unfailed and uncensored just prior to time $a j$ ).

$\Pi^{(t)}$ indicates the product over all $j$ such that $a j<t$

The interval survivor function is derived from the above equation. Next, Equation (3) verifies a Weibull assumption by checking a linear relationship on a $\log [\log ]$ v. $\log$ plot.

\section{Results}

\section{Exponential Model}

Under the exponential assumption from Equation (2), the following estimates from the casualty data are obtained:

Clearly, the CASREP and GIDEP analyses are from different types of data. The GIDEP data is for a short observation period. The ALCO-251 in this case is an emergency diesel generator. The data likely includes all failures, including those easily repaired by the operator. Conversely, the CASREP data aggregates only those failures of significant operational consequence. Both analyses yield comparable availability values, but the maintenance planning parameters MTBF and MTTR demonstrate the importance of selective data recording schemes and application.

\section{Weibull Model}

Equation (3) is used to convert the failure data to a linear relationship plotted in Figure 4. The slope of the best-fit line for this data represents $\mathrm{b}$ for a Weibull failure distribution. From Equation (3), $\alpha=20393$. 
FIGURE 4:

Weibull Plot of

Casualty Data Without

Censoring

\section{Weibull Plot of Casualty Data Without Censoring} Techniques

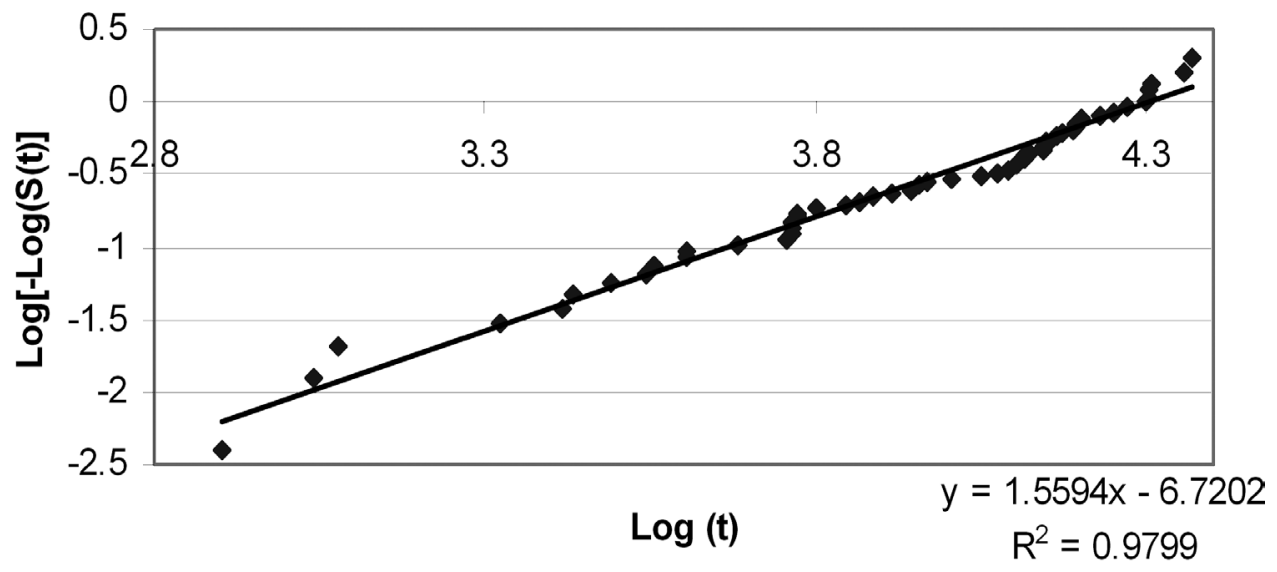

\section{Table 3}

Weibull Model Parameter Censoring Comparison

\begin{tabular}{ccc} 
& NO CENSORING & CENSORING \\
\hline$\beta$ & 1.56 & 1.38 \\
\hline$\alpha$ & 20392 & 25618 \\
\hline MTBF & 18324 hours & 23604 hours \\
\hline
\end{tabular}

\section{Censored Data Model}

Equations (6) and (3) are used to re-plot the relationship and refine our $\beta$ and $\alpha$ estimate to correct for right censoring. Table 3 compares censored and non-censored techniques with MTBF, (in this case equal to the expected value $E(t)$ of a Weibull distribution) computed using Equation (7) (Billington et al. 1991):

$$
E(t)=\int_{0}^{\infty} t \cdot \frac{\beta t^{\beta-1}}{\alpha^{\beta}} \exp \left[-\left(\frac{t}{\alpha}\right)^{\beta}\right] d t
$$

\section{Table 4}

\section{Shape Parameter for Aging Regions}

\section{OPERATING HOURS}

$$
0-7500
$$$$
7500-12500
$$

ESTIMATED AVERAGE SHAPE PARAMETER ( $\beta$ )

\subsection{5}

.85

1.82
The results show that ignoring censored techniques over-estimates the failure rate. If scheduled maintenance actions reference MTBF computed without censored-data techniques, equipment would be over-maintained because MTBF is underestimated. Inozu and Perakis (1991) arrived at similar conclusions.

\section{Failure Pattern}

In order to determine which failure pattern or patterns the engine system follows, it must be known whether $\beta$ is greater than, less than, or nearly equal to one. Figure 3 shows three regions: first, above one, then less than one, then much greater than one. Table 4 summarizes the regions. These results suggest that there is in fact an operating useful life region, and that failures do increase as the engine ages to the restoration period.

\section{Fitting the Bathtub Curve}

Subjectively, it appears that the casualty data supports a failure pattern slightly increasing, then steady useful-life, and finally an increasing rate in a wearout region. Dividing the Weibull plot into these three regions gives us three shape parameters. A numerically accu- 
rate failure rate curve can aid in planning maintenance intervals such as scheduling restoration before the end of the useful life. McCormick (1981) suggests two ways to integrate these parameters into one hazard rate model. The synthesis method weighs the influence of each of the regional failure patterns using Equation (8) below. If each individual failure pattern can be linked to a specific failure mode than synthesizing the patterns with weights relative to failure mode frequency will yield a total system failure pattern. The composite method uses Equation (9) below and follows the individual regional failure rate pattern for the appropriate time interval without the influence of weighting other failure rate patterns. The composite method is the most appropriate for our analysis, but Figure 6 shows that it does not produce the traditional "Bathtub Curve."

$$
\begin{aligned}
& f(t)=\sum_{i=1}^{I} k_{i} f_{i}(t), \\
& \text { where } 0 \leq k \leq 1, \sum_{i=1}^{I} k_{i}=1, i=1 . . I \\
& \lambda(t)=\lambda_{1}+\left(\lambda_{2}-\lambda_{1}\right) H\left(t-T_{1}\right)+\left(\lambda_{3}-\lambda_{2}\right) H\left(t-T_{2}\right), \\
& \text { where } H(x)=1, x \geq 0, \text { and } H(x)=0, x<0
\end{aligned}
$$

where $\lambda_{1}, \lambda_{2}$, and $\lambda_{3}$ are the respective interval hazard function, and $T_{1}$ and $T_{2}$ are the interval breakpoints.

\section{Conclusions and Recommendations}

The results of the failure data analysis on the Reliance class propulsion system casualties support a lifecycle with an increasing failure rate. The original hypothesis that the evidence would indicate either a constant or decreasing failure rate as operating hours increase appears false. The evidence shows that overhauls do not prevent an increasing wearout failure rate.

The exponential model is not capable of indicating an increasing or decreasing failure rate. The Weibull model shows an increasing rate. The 3-part Weibull model most accurately represents the failure data. The three intervals show an increasing, then roughly constant, then finally increasing failure rates.

Recently, the Coast Guard has pursued condition monitoring and RCM analysis to develop a preventive maintenance program (MPR Associates, Inc. 1998). Engine failure data analysis complements condition monitoring by evaluating current policies. If overhaul intervals are extended as a result, the 
FIGURE 6:

Hazard Rate (lamda) $\lambda(t)$ from 3-Part

Composite Weibull

Model

\section{Hazard Function}

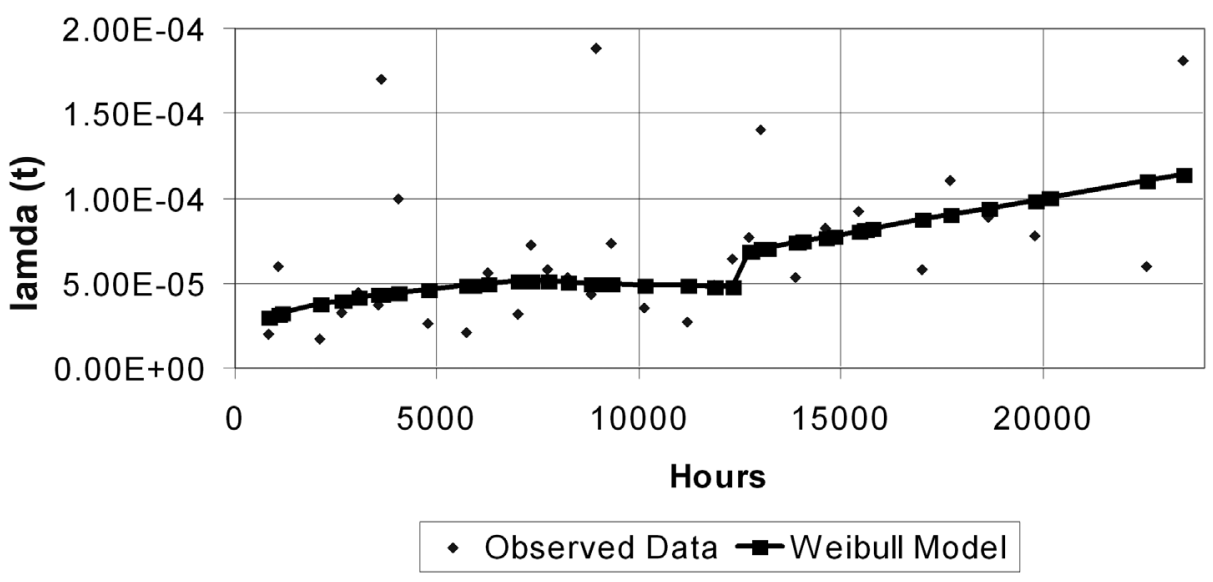

Coast Guard can re-program any deferred or saved resources. This statistical analysis brings up many questions that should be addressed in order to optimize a maintenance strategy. Specifically, integrating statistical analysis and data collection schemes with RCM and condition monitoring policies is an opportunity for continued research.

\section{REFERENCES}

Anderson and Neri. Reliability-Centered Maintenance. Elsevier Applied Science, London, 1990.

Billington, R. and Allan, R. Reliability Evaluation of Engineering Systems. Plenum Press, New York, 1992.

Burt, Mazurana, Steinle, Reick. "USCGC HEALY (WAGB 20) - A Case Study for Implementing Reliability-Centered Maintenance." [Draft]

Crowder, Kimber, Smith, and Sweeting. Statistical Analysis of Reliability Data. Chapman \& Hall, 1991.
GIDEP. Operations Manual. GovernmentIndustry Data Exchange Program, 1994.

Inozu and Perakis. "Statistical Analysis of Failure Time Distributions for Great Lakes Marine Diesels Using Censored Data." Journal of Ship Research, Vol. 35, March 1991, 73-82.

McCormick, Norman. Reliability and Risk Analysis. Academic Press, New York, 1981.

Moore and Perakis. "Development of a Diesel Engine Reliability Database (DEREL) for the U.S. Coast Guard." Marine Technology, December 1999.

MPR Associates, Inc. MPR Report 1965, "Results of Engine Analysis Demonstration on USCGC SENECA (WMEC 906)." November 1998.

Moubray, John. Reliability-Centered Maintenance Second Edition. Butterworth Heinemann, 1997.

Smith, Anthony. Reliability-Centered Maintenance. McGraw-Hill, New York, 1993.

Smith, David. Reliability Maintainability and Risk. Butterworth Heinenmann, 1997.

CHRISTOPHER MILKIE is industrial manager, USCG Integrated Support Command, Alameda, California. From 2000-2003, he was the high-endurance cutter type desk manager at the USCG Maintenance and Logistics Command, Pacific (MILCPAC). He graduated in 2000 from the University of Michigan with masters degrees in naval architecture and marine engineering (M.S.E.) and in public administration (M.P.A.). He was assigned to the USCGC Jarvis (WHEC 725) from 1996-1998as enģineer- 
in-training. He graduated from the U.S. Coast Guard Academy in 1996 with a B.S.E in naval architecture and marine engineering. He is a member of ASNE and SNAME.

DR. ANASTASSIOS PERAKIS is a tenured associate professor of naval architecture and marine engineering at the University of Michigan. He holds a Ph.D. (1982) and a masters (1980) in ocean enģineering (ocean systems operations research) from M.I.T. as well as an M.B.A. from the Sloan School of Management, M.I.T. (1982). Relevant work includes "Reliability Analysis of Marine Diesel Propulsion Systems: Towards Rational Maintenance, Repair, and Replacement Decisions," Michigan Sea Grant College Program (NOAA) from 1986-1989. He is a member of INFORMS, SNAME, Technical Chamber of Greece, International Association of Marine Economist, Chairperson NA\&OE Committee on Department of Defense Graduate Fellowship Awards.

\section{ASNE Meetings Schedule 2004/2005}

2004

September $15-16$

November TBD

2005

February 16-17

April 26-28

May 24-25

June 20-22

July TBD

August 23-25
West Coast Combat Systems 2004; "Combat Readiness for the 21st Century Fleet", ASNE Channel Islands Section, Marriott Residence Inn, Oxnard, CA (with exhibits)

Electric Warship Technologies Workshop (Classified); JHU/APL, Laurel, MD (with exhibits)

Ship Electric System Control and Reconfiguration Symposium; Theme TBD, Location TBD, Jacksonville, FL (with exhibits)

ASNE Day 2005; Theme TBD, Virginia Beach Pavilion, Virginia (with exhibits)

Intelligent Ships VI Symposium; Theme TBD, Location TBD, Philadelphia, PA (with exhibits)

Human Systems Integration Symposium 2005; Theme TBD, Location TBD, Metro Washington, DC (with exhibits)

High Speed High Performance Ships and Craft; Theme TBD, Location TBD, Seattle, WA area (with exhibits)

Fleet Maintenance Symposium 2005; San Diego Section, Holiday Inn on the Bay, San Diego, CA (with exhibits)

If you are interested in receiving information on exhibiting at one of our symposia, please contact Megan Sinesiou by phone at 703-836-6727 or via e-mail at meetings@navalengineers.org. For questions regarding registration, please contact our Meetings and Membership Assistant, Nikki Johnson, at the same number or via email at registrations@navalengineers.org. 


\title{
CALL FOR PAPERS
}

\section{Reconfiguration and Survivability Symposium 2005}

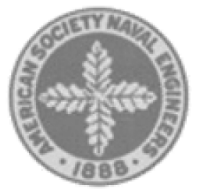

\author{
Sponsored by: \\ The American Society of Naval Engineers \\ Atlantic Beach, FL \\ February 16-18, 2005
}

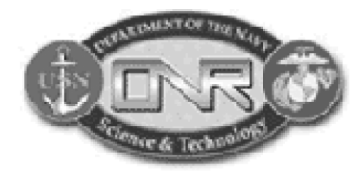

Unclassified technical papers suitable for both group presentation and publication are sought concerning the general topic of electric and mechanical distributed system reconfiguration and survivability worldwide. Technology presented is primarily desired to be used for future application in naval combatants; however, papers describing any shipboard, aerospace, commercial, and industrial application are highly desired to promote a dialogue in innovative technological solutions. This subject includes all aspects of electric machines, mechanical auxiliary equipment, sensors, actuators, energy storage, power electronics, protection \& control technologies, thermal management, modeling and simulation, ship systems integration, warfighting effectiveness, communication systems, computers, software, and related topics. Some Reconfiguration and Survivability Symposium themes of current interest are:

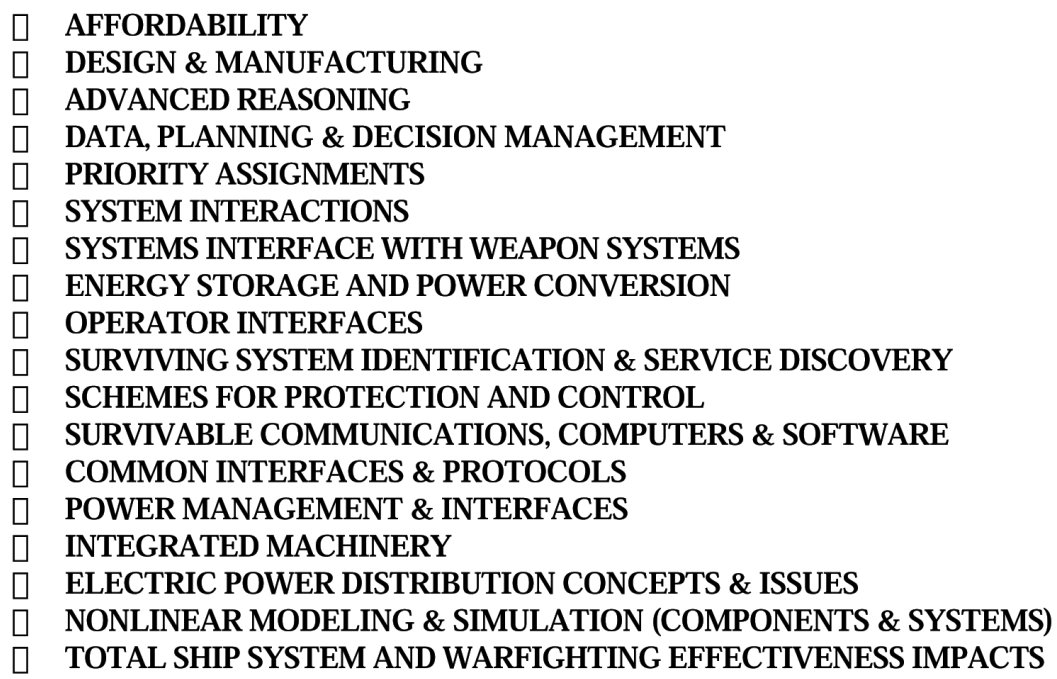

Submit a one-page Microsoft Word Format abstract/proposal to the following by e-mail (preferred), mail, or fax before June 15, 2004. Proposals should include:

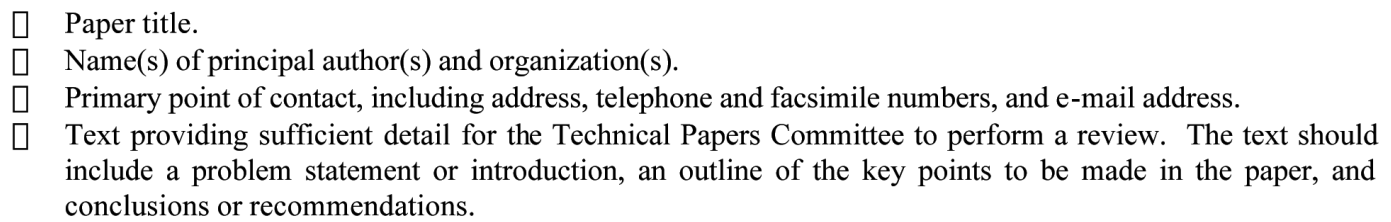

ALL PAPERS WILL BE SUBMITTED ELECTRONICALLY. Selected authors will be notified by July 1, 2004. Draft papers for review will be due September 1, 2004.

Please forward your abstracts to: Dr. Clifford Whitcomb, Technical Committee Chair

University of New Orleans

School of NAME, En 911

New Orleans, LA 70148

Email: c.whitcomb@uno.edu

Phone: 504-280-6643

Fax: 504-280-5542 